\title{
Does Language Affect Personality Perception? A Functional Approach to Testing the Whorfian Hypothesis
}

Journal of Personality $\cdot \bullet: \bullet \cdot, \cdot \bullet 2013$

(C) 2013 Wiley Periodicals, Inc.

DOI: 10.1 I I I/jopy. 12040

\author{
Sylvia Xiaohua Chen,' Verónica Benet-Martínez, ${ }^{2}$ and \\ Jacky C. K. Ng' \\ 'Hong Kong Polytechnic University \\ ${ }^{2}$ Catalan Institute for Advanced Research and Studies at Universitat Pompeu Fabra
}

\begin{abstract}
Whether language shapes cognition has long been a controversial issue. The present research adopts a functional approach to examining the effects of language use on personality perception and dialectical thinking. We propose that language use activates corresponding cultural mindsets, which in turn influence social perception, thinking, and behavior. Four studies recruited Chinese-English bilinguals ( $N=129$ in Study I, 229 in Study 2, 68 in Study 3, 106 in Study 4) and used within-subjects and between-subjects design, written and behavioral reports, and self- and other perceptions. The four studies converged to show that Chinese-English bilinguals exhibit higher dialectical thinking and more variations in self- and observer ratings of personality when using the Chinese language than when using English. Furthermore, dialectical thinking predicted more self- and other-perceived variations in personality and behavior across bilingual contexts. These results highlight the important role of culture in understanding the relations between language and cognition, and attest to the malleability of personality perception and dialectical thinking within and across individuals in response to culture-related linguistic cues.
\end{abstract}

Do the languages we speak shape the way we think? It has long been debated whether language shapes cognition. The linguistic relativity position, also known as the Sapir-Whorf or Whorfian hypothesis, argues that linguistic categories constrain and determine cognitive categorization, and thus language influences thought and behavior (Whorf, 1956). Empirical support for the linguistic relativity view derives from cross-cultural comparisons of linguistic coding, which affects cognitive processes, such as perception, attention, and memory (e.g., Brown, 1986; Özgen, 2004). For example, color and time terminology varies by culture and constrains perceptions of color and time (e.g., Boroditsky \& Gaby, 2010; Roberson, Davies, \& Davidoff, 2000). Other semantic domains such as spatial descriptions and grammatical usage are also compared across cultural groups and found to be associated with differences in cognitive tasks and behavioral responses (e.g., Fausey \& Boroditsky, 2011; Levinson, 1996; Lucy, 1997). Thus, habitual use of linguistic categories and grammatical structure drives people's cognitive representation of the world and reality.

On the other hand, the universalist theory of language posits that all languages share the same underlying structure, largely innate and hardwired into the brain and with a limited set of rules for organizing language (Chomsky, 1965). Thus, differences in linguistic structures across languages should not affect basic cognitive processes that are universal to all human beings, such as color encoding and time expressions. For instance, research on color lexicons has found similar general patterns of color across different languages, supporting the universalist theory (Berlin \& Kay, 1969). The semantic domain in many of these studies is subject to universal constraints and the associated biocognitive process that is hardwired into the neural system (Kay \& Kempton, 1984; Lucy, 1992, 1997). Some researchers even argued that thought is independent of language, as human beings do not think in the language they use to communicate but in a meta-language that is beyond any natural language (Pinker, 1994).

Though both perspectives (relativist and universalist) have received empirical support, it is important to note that most studies on this issue have focused on the semantic features of language and their effects on domain-specific perception and behavior, which are devoid of socio-emotional meanings. A given language consists of not only its linguistic properties per se, but also the social and psychological meanings attached to the use and locus of that language. Language is a communi-

This project was supported in part by the General Research Fund (PolyU $5412 / 08 \mathrm{H}$ ) from the Research Grants Council of Hong Kong.

Correspondence concerning this article should be addressed to Sylvia Xiaohua Chen, Department of Applied Social Sciences, Hong Kong

Polytechnic University, Hung Hom, Kowloon, Hong Kong.

Email: ssxhchen@polyu.edu.hk. 
cation tool for transmitting ideas, thoughts, and opinions. In this sense, language is functional (Semin, 2001). The attentiondriving function of language directs people's attention to different aspects of the world and reality. Language effects should be studied when it is in use (Chiu, Leung, \& Kwan, 2007).

In the present research, we take a functional approach to testing the Whorfian hypothesis and focus on the effects of generic properties rather than semantic features of language use on thought and behavior. Past studies examining linguistic relativity have mostly adopted a cross-cultural design and compared cross-linguistic patterns between different groups of individuals. Such designs often rely on between-culture comparisons of monolinguals, but the learning and use of additional languages offer another perspective to linguistic relativity (Pavlenko, 2011). Given the functional approach, we investigate bilinguals to uncover whether the use of two languages (within the same group of individuals) orients them to different cognitive styles and, accordingly, different perceptual foci, thereby enabling us to determine the general effects of language.

\section{Language Use and Culture}

Using a language accompanies its associated social and psychological meanings, which are embedded in a particular cultural context. Thus, language and culture are inseparable. Language is cognitively associated with cultural scripts, norms, and practices (Chen \& Bond, 2010). In other words, language influences thought and behavior by evoking a culturally congruent cognitive mindset (e.g., individualism vs. collectivism). This has been demonstrated empirically in studies where language effectively primes the corresponding cultural norms of self-concept, values, personality, and emotional expressions (e.g., Bond, 1983; Marin, Triandis, Betancourt, \& Kashima, 1983; Matsumoto \& Assar, 1992; RamírezEsparza, Gosling, Benet-Martínez, Potter, \& Pennebaker, 2006; Trafimow, Silverman, Fan, \& Law, 1997). In short, when individuals acquire different languages, they also encode different cultural systems associated with using each language. Priming one of their languages may activate the corresponding culture-specific cognitive style and in turn affect the resulting perception and behavior.

Research on social cognition has well documented that culture influences cognition (e.g., Kitayama \& Cohen, 2007; Nisbett, 2003; Oyserman \& Lee, 2008). However, to test whether language activates a culturally salient cognitive style, it would be more compelling to manipulate language use among bilinguals to see whether any found between-language differences in cognition replicate previously reported cultural group differences. Among the generic thinking styles that show well-established cross-cultural differences, dialectical thinking is a domain-general cognitive style that differs between Eastern and Western cultures.

\section{Culture and Cognitive Style}

Dialectical thinking involves interfacing and compromising contradictory facts, views, and goals (Basseches, 1984; Moshman, 1995; Peng \& Nisbett, 1999). It is regarded as a method of reasoning in Eastern philosophical tradition and a form of argument in contemporary epistemology. Rooted in folk epistemology, naïve dialecticism denotes a tolerance for contradictions, ambiguities, and inconsistencies (Peng \& Nisbett, 1999).

Different prevalence of this style of reasoning and thinking about the world, knowledge, and human life has been demonstrated across Eastern and Western cultures (Spencer-Rodgers, Williams, \& Peng, 2010). For example, relative to European Americans' self-descriptions, Chinese's self-depictions more often depict contradiction, change, and holism (SpencerRodgers, Boucher, Mori, Wang, \& Peng, 2009). Moreover, compared with Americans, Chinese prefer dialectical proverbs, dialectical resolutions of social conflict, dialectical argumentation in science, and dialectical judgments about contradictory information (Peng \& Nisbett, 1999). The extant findings on dialectical thinking indicate stable cultural differences in generic cognitive styles between the East and West.

Past work on dialecticism has explored its influence on self-views, emotional experience, psychological well-being, attitudes and evaluations, social categorization and perception, and judgment and decision making (Spencer-Rodgers, Williams, et al., 2010). East Asians exhibit higher levels of dialectical thinking and thus have more contextualized selfviews. Their conceptual self is less clearly defined and less consistent across situations (e.g., Campbell et al., 1996; Chen, English, \& Peng, 2006; Choi \& Choi, 2002; Church et al., 2008; Kanagawa, Cross, \& Markus, 2001; Kashima et al., 2005; Suh, 2002). The greater self-concept variability among East Asians has been linked to dialectical thinking and is evident in trait self-ratings and across relationship contexts (e.g., Boucher, Peng, Shi, \& Wang, 2009; Choi \& Choi, 2002; English \& Chen, 2007).

We further suggest that dialectical thinking may direct individuals' perceptual focus toward the duality and incongruity of their own behavior across interpersonal contexts. This attentional focus in turn makes these individuals see more variations in their and others' personality and behavior across different linguistic contexts, such as when using different languages or interacting with interlocutors of different ethnicities. Therefore, the present research seeks to examine how using an East Asian language activates dialectical thinking and drives individuals' attention to perceiving more differences and discrepancies in their own and others' traits, as well as perceiving more variability and inconsistency in their behavior during social interactions.

\section{The Present Research}

Boucher and O'Dowd (2011) found language priming effects on dialecticism, using samples of European Americans and 
bilingual Chinese Americans. Bilinguals who answered questionnaires in Chinese scored higher in dialectical thinking, tolerance for contradiction, changing behavior over time and context, holistic thinking, and self-concept inconsistency. Thus, using the Chinese language activates higher levels of dialectical thinking. We propose that it would also evoke corresponding perceptions of inconsistency and incongruity, which are manifested in the personality and behavior of the self and others. While bilinguals acquire their two languages, they develop prototypic perceptions about native speakers of these languages, and the prototypic perceptions may be enacted when bilinguals use the languages. Chen and Bond (2010) show that Chinese-English bilinguals are perceived as more extraverted, open, and assertive when communicating with Caucasian interviewers, consistent with these bilinguals' perceptions of prototypic English speakers' traits. When communicating with Chinese interviewers, bilinguals exhibit similar trait patterns when speaking English rather than when speaking Chinese. Thus, language use and interlocutor ethnicity evoke bilinguals' corresponding cultural mindsets, manifested in similar personality profiles characterized by the primed culture.

Though these results confirm the effects of language priming on perceived traits, they do not reflect perceptions of variability and inconsistency underlying dialecticism and do not link personality perception with dialectical thinking in the bilingual context. Therefore, built on the previous findings, we focus on personality variations in the present research and predict that when Chinese-English bilinguals use Chinese, they will perceive more differences in the personality profiles among themselves, typical native speakers of Chinese, and typical native speakers of English. Consistent with the dialectical thinking style, when using Chinese, they will perceive more variability in their personality and behavior across different linguistic contexts (i.e., speaking Chinese vs. English, talking with native speakers of Chinese vs. English). As such, language effects are examined not only in the written format of questionnaires but also in social interactions.

This research comprises four studies. Study 1 adopted a within-subject design to investigate between-language differences in dialectical thinking and personality perception within the same group of individuals (i.e., Chinese-English bilinguals). They completed self-report instruments in Chinese and English at separate time points, and their scores in dialectical thinking and personality ratings of the self, perceived native Chinese speakers, and perceived native English speakers were compared between the two language versions. Study 2 employed a between-subjects design and randomly assigned Chinese-English bilinguals to complete measures in Chinese or English on dialectical thinking and perceived personality of the self, native Chinese speakers, and native English speakers. We also tested the mediating effect of dialectical thinking to determine whether between-language differences in personality perception could be explained by dialectical thinking. To move beyond paper-and-pencil measures, Study 3 manipulated language in actual conversations. Bilingual participants in
Hong Kong conversed with fluent Chinese and Caucasian bilingual interlocutors in four conditions (two languages by two ethnicities). Self-ratings and interlocutor ratings were derived from interpersonal communications to identify differences across linguistic contexts and shed light on the manifestations of dialectical thinking in perceptions of personality and behavior, which are unexplored domains in the dialecticism literature. To demonstrate that language effects constitute more than semantic features, Study 4 used a thin-slicing judgment method by recruiting participants (as judges) to view video segments of Chinese-English bilinguals (as targets) in actual conversations, and asked judges to rate the personality traits and cultural orientations of the targets with the voice muted. If personality differences could be observed in nonverbal format, we would infer that bilinguals exhibit more variability in their behavior when using Chinese because the judges could not base their judgment on the verbal content of the conversations. Taken together, the four studies attempt to show that the use of language, whether written or spoken, verbal or nonverbal, affects general cognitive styles, as well as corresponding personality perception and communicative behavior.

\section{STUDY I}

In the first study, Chinese-English bilinguals completed dialectical thinking and personality measures in both languages at separate time points. To ensure the equivalence of the two language conditions, high levels of English proficiency were required for participation. We hypothesized that these bilinguals would score higher on dialectical thinking and display more differences in their trait ratings in Chinese than in English. Given the notion of dialectical thinking, we compared the magnitude of between-language differences in an aggregate sense rather than the direction of difference for each personality factor. Thus, the averaged absolute value of difference scores was used to achieve this purpose.

\section{Method}

Participants. One hundred twenty-nine Chinese-English bilinguals (50 males and 79 females) were recruited from the Chinese University of Hong Kong. Their mean age was 20.54 $(S D=1.63)$. We selected participants who obtained a $\mathrm{C}$ or above on both the Hong Kong Certificate of Education Examination and the "Use of English" examination in the Advanced Level Examination in Chinese and English (Hui \& Cheng, 1987).

\section{Measures}

Dialectical Self Scale. The Dialectical Self Scale (DSS; Spencer-Rodgers, Srivastava, et al., 2010) was employed to assess the tendencies to view oneself as malleable (e.g., "I often find that my beliefs, attitudes and personality will change under different contexts") and tolerate contradictions (e.g., 
"When I hear two sides of an argument, I often agree with both"). Participants were asked to rate 32 items on 7-point Likert scales ranging from 1 (strongly disagree) to 7 (strongly agree). The DSS has been shown to possess adequate crosscultural validity and reliability (e.g., Hamamura, Heine, \& Paulhus, 2008; Hui, Fok, \& Bond, 2009; Spencer-Rodgers et al., 2009) and has previously been examined in bicultural contexts (Chen, Benet-Martínez, Wu, Lam, \& Bond, 2013). After recoding the reverse items, DSS scores were derived from the mean responses across items, with higher scores reflecting higher levels of naïve dialecticism $(\alpha=.81$ for Chinese and .78 for English).

Sino-American Person Perception Scale. Participants rated their own personality and that of typical native speakers of Chinese and typical native speakers of English (primarily British and Americans). The Sino-American Person Perception Scale (SAPPS; Yik \& Bond, 1993) is a personality instrument based on the Western Five-Factor Model (McCrae \& Costa, 1985, 1987; Norman, 1963) and indigenous Chinese adjective checklists (Lew, 1985; Yang \& Bond, 1990). The scale, which has both Chinese and English versions, consists of 32 bipolar adjectives on a 7-point scale measuring the following eight dimensions: Emotional Stability, Extraversion, Application, Openness to Experience, Assertiveness, Restraint, Helpfulness, and Intellect $(\alpha=.80, .82, .73, .84, .67, .69, .64$, and .62, respectively, for the Chinese version and $\alpha=.74, .81, .66, .78$, $.46, .46, .55$, and .61 , respectively, for the English version).

Procedure. At Time 1, participants were randomly assigned to two groups. Half completed the English version of the questionnaire and the other half, the Chinese version. All participants were instructed to report demographic information such as age, year, and major of study. Confidentiality was ensured. At Time 2, after two to three weeks, members of the two groups completed the other language version of the same measures. They were thanked and debriefed.

\section{Results and Discussion}

A dependent samples $t$ test was conducted to examine differences in dialectical thinking between the Chinese and English versions, $t(118)=5.90, p<.001, d=0.53$. Consistent with our hypothesis, bilinguals reported significantly more dialectical thinking ( $M=4.25, S D=0.48)$ when responding in Chinese rather than in English $(M=4.09, S D=0.44)$. This result mirrors the established cross-cultural differences in dialecticism (i.e., Chinese people being more tolerant of contradiction than Americans; Spencer-Rodgers, Williams, et al., 2010) and supports the effect of language use on cognitive styles.

Furthermore, we examined language effects on differences in personality perception. First, the absolute value of difference score between self-ratings and ratings of perceived Chinese speakers was computed for each personality factor. Then a mean difference score was derived by averaging the absolute values of difference scores across eight factors. Similarly, we obtained a mean difference score between self-ratings and ratings of perceived English speakers and that between ratings of perceived Chinese and English speakers, respectively, across eight factors. A total difference index was then computed by averaging the three mean difference scores, which reflected bilinguals' discrepancy in perceiving the personality of the self and others. Finally, we conducted a dependent samples $t$ test to compare the total difference index between the two languages, $t(118)=2.52, p<.05, d=0.23$. Bilinguals reported significantly more differences in trait ratings in Chinese $(M=1.30, S D=0.43)$ than in English $(M=1.23, S D=0.43)$. These results indicate that written language influences cognitive style and personality perception.

\section{STUDY 2}

Study 1 found between-language differences in dialectical thinking and personality perception, but the design of the study does not allow us to draw causal conclusions. Moreover, it has not confirmed that the mechanism underlying differences in personality perception could be explained by dialectical thinking. Thus, Study 2 adopted an experimental design to manipulate language and randomly assign Chinese-English bilinguals to complete dialecticism and trait measures in Chinese or English. We hypothesized that compared with those responding in English, bilinguals who responded in Chinese would score higher on dialectical thinking and exhibit more differences in perceived personality of themselves, typical native speakers of Chinese, and typical native speakers of English. The mediation effect of dialectical thinking was tested to examine whether it accounted for the relation between language and differences in personality perception.

\section{Method}

Participants and Procedure. Two hundred twenty-nine Chinese-English bilinguals (102 males and 127 females) from Beijing Normal University voluntarily participated in this study. Participants' mean age was $22.24(S D=2.68)$. Note that admission into Beijing Normal University, a very competitive university in China, requires high levels of English-language proficiency. Mainland Chinese students from prestigious universities show bilingual competence in Chinese and English (Chen, Benet-Martínez, \& Bond, 2008). Participants were randomly assigned to complete a packet of questionnaires in English ( $n=98 ; 50$ males and 48 females) or in Chinese ( $n=131 ; 52$ males and 79 females). They were assured of confidentiality at the beginning, and debriefed and thanked at the end of the study.

\section{Measures}

Language Proficiency and Usage. Participants completed separate English- and Chinese-language scales 
(Benet-Martínez \& Haritatos, 2005) tapping the following domains: (a) language ability (e.g., "Rate your overall Chinese/English language ability"); (b) past and present language usage (e.g., "How much have you used Chinese/English in general as an adult?"); and (c) media exposure (e.g., "How often do you watch TV shows/movies in Chinese/English?"). The two scales consist of 14 items rated on 6-point Likert scales, with those items tapping language ability ranging from 1 (very little ability) to 6 (very high ability) and the rest from 1 (almost never) to 6 (very often). In this study, Cronbach's alphas for the Chinese and English scales were .62 and .78 for the Chinese group, and .69 and .63 for the English group.

Dialectical Self Scale. The DSS (Spencer-Rodgers, Srivastava, et al., 2010) was the same as in Study $1(\alpha=.78$ for Chinese and .75 for English in this study).

Big Five Inventory. Participants provided self-reports and also rated the personality traits of typical native speakers of Chinese and typical native speakers of English (primarily British and Americans). The 44 items of the Big Five Inventory (BFI; John, 1990; John \& Srivastava, 1999) measure the most prototypical traits associated with the Big Five factors (see John, 1990), namely, Extraversion, Agreeableness, Conscientiousness, Neuroticism, and Openness to Experience $(\alpha=.70$, $.64, .77, .83$, and .81 , respectively, for the Chinese group and $\alpha=.54, .63, .68, .66$, and .71 , respectively, for the English group). Responses to each target were anchored on 5-point Likert scales ranging from 1 (strongly disagree) to 5 (strongly agree).

\section{Results and Discussion}

We first examined the equivalence of the two experimental groups on language proficiency and usage. Independent samples $t$ tests found no significant differences in participants' reported Chinese proficiency, $t(227)=-1.40$, Chinese usage, $t(227)=0.10$, English proficiency, $t(227)=-0.27$, or English usage, $t(227)=0.32$, all $p \mathrm{~s}>.05$. Differential language ability is therefore an unlikely cause of differences in responses as a function of questionnaire language.

An independent samples $t$ test was conducted to examine differences in dialectical thinking between the Chinese and English conditions, $t(226)=3.12, p<.05, d=0.53$. As hypothesized, bilinguals who were assigned to the Chineselanguage condition scored significantly higher on dialectical thinking $(M=4.06, S D=0.60)$ than those in the English condition $(M=3.83, S D=0.52)$. This finding from a betweensubjects design replicates that of Study 1, which relied on a within-subject design.

Next, we examined language effects on differences in personality perception. Using a similar method as in Study 1, a total difference index was computed by averaging the absolute values of difference scores between self-ratings, ratings of Chinese speakers, and ratings of English speakers across five personality factors. We conducted an independent samples $t$ test to compare the total difference index between the two language conditions, $t(226)=2.57, p<.05, d=0.35$. Bilinguals who were assigned to the Chinese-language condition reported significantly more differences in trait ratings $(M=0.77, S D=0.26)$ than those in the English condition $(M=0.68, S D=0.26)$.

Moreover, we tested whether dialectical thinking mediated the relation between language and perceived personality differences, using the four steps suggested by Baron and Kenny (1986) and Judd and Kenny (1981). First, language significantly predicted the total difference index, $R^{2}=.03, F(1,227)=6.61$, $\beta=.17, p<.05$. Second, language significantly predicted dialectical thinking, $R^{2}=.04, F(1,227)=9.73, \beta=.20, p<.01$. Third, dialectical thinking significantly predicted the total difference index, $R^{2}=.03, F(1,226)=7.08, \beta=.17, p<.01$. Fourth, the effect of language on the total difference index was still significant after controlling for dialectical thinking, $\Delta R^{2}=.02, \Delta F(1,226)=4.37, \beta=.14, p<.01$, indicating partial mediation. Finally, we used the Sobel test (Sobel, 1982) to confirm whether the indirect effect of language on the total difference index through the mediation of dialectical thinking was significant. The Sobel statistic, $z=2.02, p<.05$, indicated that dialectical thinking partially mediated the link between language and the total difference index.

These results show that bilinguals using the Chinese language reported higher levels of dialectical thinking and more differences in personality perception. The underlying mechanism that can partially explain the perceived differences is the activation of dialectical thinking in the Chinese language.

\section{STUDY 3}

Studies 1-2 have confirmed the impact of written language on dialectical thinking and personality perception. The measures, however, were paper-and-pencil self-reports. Less is known about the consequences of dialectical thinking on behavioral manifestations. Study 3 used actual conversations to examine the effects of spoken language. Speaking Chinese and talking with a Chinese interlocutor create a Chinese linguistic context, whereas speaking English and talking with a Caucasian create an English context. The involvement of interlocutors also provides an additional perspective other than the bilinguals themselves. To control for the possible confound of gender effect on social interactions, Study 3 standardized female bilinguals as participants and male bilinguals as conversational partners.

In this study, we hypothesized that Chinese-English bilinguals higher in dialectical thinking would perceive greater cross-linguistic differences in their own personality and behavior. That is, we predicted a link between dialectical thinking and perceiving oneself as having more differences in personality and acting differently when speaking Chinese versus English and when talking with Chinese versus Caucasian interlocutors. We also hypothesized that this pattern of differences 
would be observed by their conversational partners, as well as by naïve observers (who did not engage in the conversations with our participants).

\section{Method}

Participants. The sample consisted of 68 female ChineseEnglish bilinguals $\left(M_{\text {age }}=20.41, S D=1.50\right)$ who were recruited from the Chinese University of Hong Kong using the same criteria from Study 1.

We also recruited two Caucasian and two Chinese interviewers who were fluent in both Cantonese and English. All of them were between 20 and 30 years old, comparable in height and physical attractiveness. These interviewers were trained to standardize their nonverbal behaviors, such as paralinguistics, kinesics, and gazing, during the conversations so that participants' perceived differences in personality and behavior would not be due to interviewers' demand characteristics.

The interviewers and all research assistants were blind to the hypotheses of this study. The three research assistants, who had met all the interviewers, rated the physical attractiveness of the four interviewers on a 5-point Likert scale ranging from 1 (least attractive) to 5 (most attractive). A one-way repeatedmeasures analysis of variance (ANOVA) showed that ratings of physical attractiveness did not differ across interviewers, $F(2,1)=.25, p>.05$.

Measures and Procedure. At first, participants completed demographic information and the Dialectical Self Scale (Spencer-Rodgers, Srivastava, et al., 2010) in Chinese $(\alpha=.79)$. After a few weeks, participants conversed with one Caucasian interviewer and one Chinese interviewer in English and Cantonese for about 10 minutes, separately. In other words, each participant took part in four conditions: talking with a Caucasian interlocutor in English, with a Caucasian interlocutor in Cantonese, with a Chinese interlocutor in English, and with a Chinese interlocutor in Cantonese. The order of language and interlocutor was counterbalanced.

To control for the content of conversations across conditions, four sets of questions were designed in parallel forms and in both languages, such that each participant responded to comparable but not identical questions across the four conditions. The content was general information about themselves, their hobbies, and social activities. For example, after a brief introduction to the procedure, participants were asked to talk about sports/movies/songs/paintings, respectively, for each condition (with four sets of scripts), and to describe their favorite sport/movie/song/painting and why they liked it, as well as their favorite sports star/movie star/singer/painter.

Self-Rated Cross-Linguistic and Cross-Interlocutor Differences. After the conversations, participants were asked to answer a set of questions in Chinese on the extent to which they perceived themselves feeling, thinking, and behaving dif- ferently across languages and interlocutor ethnicities, and the extent to which they thought that others perceived them as different across languages and interlocutor ethnicities. The items were as follows: "Do you feel differently when you use Chinese and English?" "Do you think differently when you use Chinese and English?" "Do you behave differently when you use Chinese and English?" "Do you perceive your personality differently when you use Chinese and English?" "Do other people perceive you as a different person when you use Chinese and English?" and "Do you perceive yourself to be a different person when you speak English to a native speaker and a second-language speaker of English?" These six items were anchored on a 5-point Likert scale $(\alpha=.87)$ ranging from 0 (no difference), 1 (slightly different), and 3 (moderately different), to 5 (very different).

Interlocutor-Rated Cross-Linguistic and CrossInterlocutor Differences. After the interlocutors conversed with each participant in both languages, they were asked to complete questions in their native language on the extent to which they perceived the participant behaving differently across languages (e.g., "Did the participant behave differently when s/he used Cantonese and English?" and "Do you perceive his/her personality to be different when he/she used Cantonese and English?"). The two items were anchored on a 5-point scale $(\alpha=.64)$ ranging from 0 (no difference), 1 (slightly different), and 3 (moderately different), to 5 (very different).

Observer Ratings. The interviews were recorded by camcorders, with each condition saved in a separate video file for later review. Thus, there were four video files for each participant, one for each condition. After all participants were interviewed, two Chinese-English bilingual observers were recruited to review the video files separately and complete a rating sheet independently for each participant under each condition. As the camera was focused only on the participants, the interviewers were not filmed and their ethnicity was not revealed to the observers.

To provide a tangible personality scoring scheme for observer ratings, a representative word from the eight personality dimensions as measured by the SAPPS was selected out of the four items defining each personality dimension (e.g., extraverted, open, and assertive). If a representative word was difficult to find from the four items, a key word was used to represent the personality factor (e.g., restrained for the Restraint factor). The observers independently completed a rating sheet in Chinese after they reviewed the video file of a participant in each of the four conditions. They were asked to judge the participant's traits from the video segment (e.g., "Did the participant seem extroverted?") and to circle their answers based on a 6-point scale ranging from 1 (strongly disagree) to 6 (strongly agree). Thus, four sets of ratings were collected for each participant, one set for each condition. 


\section{Results and Discussion}

Self-Rated Differences. The self-rated cross-linguistic difference scores in personality and behavior were averaged across the six items to compute a general index of self-rated cross-linguistic discrepancy. This index $(M=1.98, S D=1.13)$ was regressed on dialectical thinking $(M=4.34, S D=0.45)$, controlling for the possible effect of age. As hypothesized, dialectical thinking significantly predicted self-rated differences, $\Delta R^{2}=.12, \Delta F(1,65)=8.80, \beta=.35, p<.01$. Bilinguals who scored higher on dialectical thinking perceived themselves to behave, think, and feel differently when speaking Chinese versus English and when talking with interlocutors of different ethnicities.

Interlocutor-Rated Differences. The interlocutor-rated cross-linguistic difference scores were computed by averaging interlocutors' ratings across the two items. This difference index $(M=1.54, S D=0.74)$ were regressed on participants' dialectical thinking, controlling for age. Consistent with the results found for participants' self-ratings, dialectical thinking significantly predicted interlocutor-rated cross-linguistic differences, $\Delta R^{2}=.13, \Delta F(1,64)=9.34, \beta=.36, p<.01$. Interlocutors perceived bilinguals who scored higher on dialectical thinking as behaving differently and exhibiting more differences in personality when conversing in Chinese versus English.

\section{Relations Between Self- and Interlocutor-Rated Differ-} ences. The cross-linguistic personality differences perceived by participants and interlocutors were significantly correlated, $r=.26, p<.05$. Interestingly, the magnitude of this correlation is comparable to the mean inter-observer correlations of .22-.25 found in previous studies on trait ratings (John \& Robins, 1993). The correlation between self-perceptions and other perceptions provided stronger evidence for behavioral variability across bilingual contexts, as these two sources do not share common method variance. The observations from interlocutors converged with participants' self-perceptions, indicating that the more participants evaluated themselves in dialectical terms, the more differently they acted across the linguistic contexts.

Observer Ratings. To further demonstrate that self-perceived cross-linguistic differences in personality are observable, we examined differences rated by individuals who did not engage in the conversations with participants. First, the absolute value of difference score between conversing with Caucasian versus Chinese interlocutors in Cantonese was computed for each personality factor. The mean difference score for Cantonese was derived by averaging difference scores across eight factors. Similarly, the mean difference score was computed for the English language. Then a dependent samples $t$ test was conducted to compare the mean difference scores between the two languages, $t(71)=6.83, p<.001, d=1.07$. Observers perceived participants' personality as more different when participants conversed in Cantonese $(M=0.66, S D=0.27)$ rather than in English $(M=0.38, S D=0.22)$. Apparently, speaking the Chinese language elicits more variability in bilinguals' social interactions with people from different cultural backgrounds, which is consistent with dialectical thinking style. Personality differences perceived by interlocutors and observers confirm that the variability is not only in bilinguals' inner thought but also in their communicative behavior, thus observable to other people.

\section{STUDY 4}

Studies 1-3 show that written and spoken language activate a culture-embedded cognitive style (dialectical thinking), which in turn gives rise to higher intra- and interpersonal variability in personality perception. Though our Studies 1-3 extended the investigation of dialectical thinking effects to language use, the written or spoken language in these studies still contained verbal content. Similarly, past research examining the relations between language and cognition to test the Whorfian hypothesis has primarily focused on the effects of semantic features of language. To ascertain that culture-embedded cognitive styles and culture-congruent response styles are affected by not only the verbal features but also the nonverbal features of language use, in the next study, we adopted the thin-slicing approach to person perception (Ambady \& Rosenthal, 1992) and examined the relationships between dialectical thinking and observable cultural characteristics across languages.

A thin slice refers to a brief segment or clip extracted from a longer video recording of an individual interacting with others or performing a task (Oltmanns, Friedman, Fiedler, \& Turkheimer, 2004). It constitutes a dynamic sample of the individual's behavior, and thin slice judgment is based on the assumption that brief observational samples capture representative elements of the ongoing behavior stream and therefore provide a window into the totality of interaction (Bernieri \& Gillis, 2001). Predictive accuracy of the thin slices of expressive behaviors was meta-analyzed on diversified outcomes across 38 studies, obtaining an overall effect size $(r)$ of .39 . This effect size is comparable with the overall effect size $(r)$ of .31 from a previous meta-analysis of "thick slice" ratings on similar outcomes (Wiggins, 1973), indicating a favorable accuracy of thin-slicing ratings (Ambady \& Rosenthal, 1992). To achieve the most reliable thin-slicing judgment, 30- to 60 -second segments of behavior were suggested $(r=.57)$. Among different formats of thin slice segments, judges yield greater overall accuracy in nonverbal format than in verbal format ( $r=.41$ vs. $r=.34$; Ambady \& Rosenthal, 1992). In addition, Wright and Drinkwater (1997) proposed that similarity between judges and targets in terms of demographic attributes, such as age, education level, and socioeconomic status, improved the accuracy in interpersonal judgments.

In this study, we recruited Chinese-English bilinguals as judges and asked them to view brief video segments extracted from Study 3 of participants (targets) engaging in conversations. Then the judges rated the personality traits and cultural 
orientations of the targets. We hypothesized that when targets spoke Chinese, their language-activated cognitive style, i.e., dialectical thinking, would be more salient, such that it is manifested in their personality and behavior, and their cultural characteristics would be more outwardly observable. Accordingly, targets would display more differences in their personality in relation to cultural orientations (agentic vs. communal traits) when using Chinese, and the predictive power of targets' dialectical thinking on their cultural orientations (individualistic vs. collectivistic) perceived by judges would be stronger when targets communicated in Chinese rather than in English.

As both Cantonese and a Chinese interlocutor may serve as cultural primes that activate higher levels of dialectical thinking, we focused on language effects by holding interlocutor ethnicity constant. To avoid "double primes," we selected video recordings of conversations only with Caucasian interlocutors to compare differences between using Cantonese versus English.

\section{Method}

Participants and Procedure. In this study, we recruited 106 Chinese-English bilinguals from the Hong Kong Polytechnic University as judges (39 males, 67 females; $M_{\text {age }}=20.93$, $S D=2.06)$ and randomly selected 15 participants from Study 3 as targets. Since both judges and targets were ChineseEnglish bilinguals in Hong Kong, the similarity between them may improve the accuracy of interpersonal judgment. For each target, a 45-second segment with sound muted was extracted from the full session of his or her videotaped conversation, which lasted about 10 minutes for each condition. Each segment started from the first sentence that the targets spoke after they were asked to describe themselves.

All judges recruited were randomly assigned into two conditions. One condition used video segments of targets conversing with Caucasian interlocutors in Cantonese, and the other condition used those with Caucasian interlocutors in English. In each condition, judges were invited to a lab and instructed to watch 15 video clips, each of which lasted for 45 seconds. Before they started, two 15 -second video clips that corresponded to their condition were provided to judges for practice. The order of the 15 video clips was counterbalanced across the two conditions. After watching each video clip on a computer, judges rated the target's personality traits and cultural orientations. After the experiment, the judges were thanked and debriefed.

The current research design adopted a multilevel structure with multiple ratings (Level 1 within person) nested within people (Level 2 between person), as each of the 106 judges gave 15 sets of ratings. One of the judges was excluded from subsequent analyses due to missing responses.

\section{Measures}

Judges' Rating Sheet. Following each video clip, judges were instructed to rate two items on the target's cultural ori- entations (i.e., "individualistic" and "collectivistic") using 7-point Likert scales ranging from 1 (extremely low) to 7 (extremely high). Similar to observers' ratings in Study 3, judges rated eight personality dimensions extracted from the Sino-American Person Perception Scale (Yik \& Bond, 1993). Since judges only rated each target's personality once, there were no total difference scores across different perceived groups (like participants' ratings in Studies 1-2) or between conversing with Chinese versus Caucasian interlocutors (like observers' ratings in Study 3). Instead, we selected six dimensions corresponding to cultural orientations to compute a difference index, including agentic traits of extraversion, assertiveness, and openness to experience (based on the literature associated with individualistic cultural orientation) and communal traits of restraint, application, and helpfulness (based on the literature associated with collectivistic cultural orientation; Chen \& Bond, 2010; Ho \& Chiu, 1994; Markus \& Kitayama, 1991; Schwartz, 1994; Triandis, 1989, 1993).

Targets' Questionnaire. Targets' self-report on dialectical thinking was collected from Study 3.

\section{Results}

We examined whether judges perceived more differences in targets' personality when targets used Chinese in the filmed conversations. First, judges' ratings of agentic and communal traits for each target were computed by averaging ratings of three agentic factors and those of three communal factors. Second, we computed aggregated agentic traits and communal traits for each judge by averaging judges' ratings of agentic and communal traits across 15 targets, respectively. Third, a total difference index was derived from the absolute values of difference scores between aggregated agentic versus communal traits. Then we conducted an independent samples $t$ test to compare the total difference index between the Cantonese and English conditions, $t(104)=2.40, p<.05$. The difference index was significantly higher in Cantonese $(M=0.95$, $S D=0.37)$ than in English $(M=0.78, S D=0.35)$, indicating that targets exhibited more discrepancies between their culture-related traits (agentic vs. communal) when they communicated in Chinese rather than in English, and that these discrepancies were observable to judges.

Next, we tested whether targets' dialectical thinking predicted their observable cultural characteristics as perceived by judges (see Figure 1). Due to the multilevel structure of the data with judgment of 15 targets (Level 1 within person) nested within people (Level 2 between person), multilevel analysis was employed using Mplus version 5.1 (Muthén \& Muthén, 2007). Multilevel analysis is preferred since it can provide more accurate parameter estimates and handle missing data. To account for the nested structure, models were fitted with random intercepts and fixed slopes. 


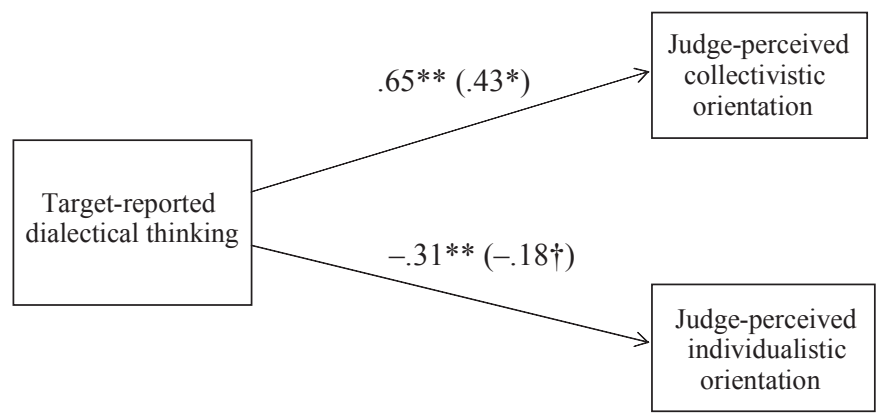

Figure I The configural model across Cantonese and English conditions. $* * p<.001$. $* p<.05 . \dagger p<.10$. (Coefficients in parentheses are for the English condition.)

All models in this study were estimated with the robust maximum likelihood estimation method with the SatorraBentler correction (MLR) to adjust for multivariate nonnormality of the data, by taking into account model estimation method and sample kurtosis values (Satorra \& Bentler, 1988). A model with comparative fit index (CFI) greater than .90 and root-mean-square error of approximation (RMSEA) less than .08 is considered an acceptable fit to the data (Hoyle, 1995).

For the test of path equivalence across conditions, multiplegroup analysis was employed, following increasingly restrictive multilevel models to evaluate invariance of the paths across conditions. In Step 1, baseline models in each of the conditions were fitted. In Step 2, a multilevel model to the total samples with no cross-sample constraints imposed (configural) was fitted and then compared with a more stringent model to the total samples with equivalent paths constrained. The criterion $(\triangle \mathrm{CFI} \geq 0.01)$ was adopted in the invariance test across conditions. Cheung and Rensvold (2002) showed that model complexity and sample size did not affect the change of CFI. They concluded that a $\Delta$ CFI value of higher than 0.01 indicated a more constrained model, resulting in a significant drop of fit, and thus the constrained parameters were not equivalent across groups.

In Step 1, both baseline models in the Cantonese and English conditions fit the data well (see Table 1). In Step 2, multiple-group analysis was conducted to compare the associations of targets' dialectical thinking and their cultural orientations rated by judges across the Cantonese and English conditions. The configural model with two structural paths allowed to be unequal across conditions was compared to the model with two paths constrained to be equal across conditions. The configural model with target-rated dialectical thinking as predictor as well as judge-perceived collectivistic and individualistic orientations as outcomes fit the data well, $\chi^{2}(2)=8.06$, CFI $=.94$, RMSEA $=.06$.

In the Cantonese condition, target-reported dialectical thinking was significantly and positively related to judgeperceived collectivistic orientation, with a path coefficient of $0.65, p<.001$, but negatively related to individualistic orien-
Table I Results of Testing Invariance of the Multilevel Model Across Conditions

\begin{tabular}{|c|c|c|c|c|c|}
\hline & $N$ & $\mathrm{R}-X^{2}$ & d.f. & $\mathrm{R}-\mathrm{CFI}$ & R-RMSEA \\
\hline \multicolumn{6}{|l|}{ Step I: Baseline model } \\
\hline Cantonese condition & 742 & $4.17 *$ & I & 0.96 & 0.07 \\
\hline English condition & 742 & $3.94 *$ & I & 0.92 & 0.06 \\
\hline \multicolumn{6}{|l|}{$\begin{array}{l}\text { Step 2: Invariance test } \\
\text { across conditions }\end{array}$} \\
\hline $\begin{array}{l}\text { Configural model } \\
\text { (unequal paths) }\end{array}$ & $\mathrm{I}, 484$ & $8.06 *$ & 2 & 0.94 & 0.06 \\
\hline $\begin{array}{l}\text { Constrained model } \\
\text { (equal paths) }\end{array}$ & $\mathrm{I}, 484$ & $11.48 *$ & 4 & 0.92 & 0.05 \\
\hline
\end{tabular}

Note. $*_{p}<.05$.

tation, with a path coefficient of $-0.31, p<.001$. In the English condition, the positive relationship between target-reported dialectical thinking and judge-perceived collectivistic orientation was also significant, with a path coefficient of 0.43 , $p<.05$, whereas target-rated dialectical thinking was marginally and negatively related to judge-derived individualistic orientation, with a path coefficient of $-0.18, p=.08$.

The constrained model with equal paths imposed had poorer fit, $\chi^{2}(4)=11.48, \mathrm{CFI}=.92$, than the configural model with unequal paths allowed, though it could be regarded as having adequate fit to the data. According to the criteria of fit difference suggested by Cheung and Rensvold (2002), the model with equal paths constrained yielded a significant drop of fit $(\triangle \mathrm{CFI}=.02)$ compared with the configural model with unequal paths allowed. Therefore, the strengths of pathways between dialectical thinking and cultural orientations differed between two conditions - significantly stronger in Cantonese than in English. Since dialectical thinking was rated by targets and cultural orientations were rated by judges, the stronger predictive power in the Chinese condition indicates that when targets used the Chinese language, their culture-embedded cognitive style (dialectical thinking) was more strongly manifested in observable cultural characteristics (collectivistic vs. individualistic orientations) .

Taken together, differences in culture-related traits and predictions of cultural orientations were more observable in Chinese than in English when judges did not hear the verbal content of conversations. These characteristics must have been displayed in targets' communicative behavior, therefore confirming the effects of language use beyond its linguistic features.

\section{GENERAL DISCUSSION}

In the present research, four studies examined how dialectical thinking, personality perception, and communicative behavior varied with the use of two languages. Language effects were supported among Chinese-English bilinguals in Study 1. When using Chinese, bilinguals scored higher on dialectical 
thinking and reported more differences in perceiving the personality traits of the self, typical native speakers of Chinese, and typical native speakers of English rather than when using English. These results obtained from a within-subject design in Study 1 converged with those using a between-subjects design in Study 2. Moreover, dialectical thinking partially mediated the relation between language and personality perception, in part unpacking between-language differences in perceiving the prototypic personality profiles of the self and speakers of their two languages. Study 3 incorporated self- and other perspectives to show that bilinguals higher on dialectical thinking exhibited more variations in their communicative behavior and personality when they conversed in different languages and interacted with speakers of different ethnicities, as perceived by themselves, interlocutors, and observers. Based on thinslicing judgments in nonverbal format, Study 4 revealed that bilinguals' discrepancies in cultural characteristics (agentic vs. communal traits) as perceived by the judges were more pronounced in Cantonese than in English. The predictive power of dialectical thinking on cultural orientations was stronger in the Chinese condition than in the English condition, further demonstrating that language effects are not limited to semantic features.

\section{Language Influences Cognition}

The issue of whether language shapes cognition has attracted constant attention from philosophers, anthropologists, linguists, and psychologists and engaged them in hot debates, which have important implications for politics, law, and religion (Boroditsky, 2009; Pavlenko, 2011; Semin, 2001). One of the major controversies is relativism versus universalism. Whereas the universalist perspective emphasizes similarities across different language groups, the relativist perspective highlights particulars and differences between languages. Though the notion that language and thought processes are intertwined may appear sensible, empirical work lending support to the claims is scarce, as it is difficult to formulate testable ideas and much of the initial evidence comes from anecdotal examples of observing specific properties of language (Brown, 1986). A closer examination of the empirical findings shows that both similarities and differences are evident in the domains under study. For instance, stages of language acquisition and development share a common sequence across languages, but universal grammar is not apparent at the babbling stage (Foster-Cohen, 1999; Sternberg, 1999); restrictions on color perception are universal, but different languages divide up the color spectrum differently (Boroditsky, 2009). Thus, the relativist account and the universalist account are not conclusive in determining whether and how language shapes cognitive processes.

We took a functional approach to addressing this issue. Language not only contains a constellation of linguistic categories, grammatical structures, and abstract rules, but is also used as a tool to communicate thoughts and ideas along with goals, motives, and intentions (Semin, 2001). Language use guides people's perceptual focus toward different aspects of the self and the world, and influences the way they see, think, and act. In this light, the study of language effects should not be limited to linguistic properties, as they are symbolic representations of reality, but ought to be placed in actual contexts of usage, especially social settings. Written language has often been employed as a prime in social cognition research (Oyserman, 2011), and we suggest that spoken language and interlocutor ethnicity may activate the functional features of language, which are only enacted in social interactions.

\section{Culture Is a Key to the Puzzle}

As language and culture are inseparable, culture can be a key to understanding the relations between language and cognition. Cultures differ in the cognitive processes they foster and enact. In thinking, Westerners are more analytic, focusing on objects and their properties; Easterners are more holistic, emphasizing contexts and relationships between elements (e.g., Nisbett, Peng, Choi, \& Norenzayan, 2001). In attention, Westerners focus more on the figure that stands out from the surrounding context, whereas Easterners attend to the ground where the figure is embedded (e.g., Kitayama, Duffy, Kawamura, \& Larsen, 2003; Masuda \& Nisbett, 2001). In perception, Westerners are field independent, relying on internal frames of reference to analyze the physical environment; Easterners are field dependent, orienting themselves in space to external frames of reference (e.g., Berry, 1989/1990; Ji, Peng, \& Nisbett, 2000; Mishra, 2001). In reasoning, Westerners use logical rules, emphasizing correctness and preferring categorizations, whereas Easterners adopt dialectical approaches, tolerating contradictions and seeking the Middle Way (e.g., Bagozzi, Wong, \& Yi, 1999). These East-West differences reflect variations in generic cognitive styles, one of which is dialectical thinking that affects how people perceive the self, others, and the world. This cognitive style also predicts flexibility in coping with changing situational demands (Cheng, 2009).

Our findings indicate that language use, be it written or spoken, could evoke certain patterns of thought and behavior, such that bilinguals display high levels of dialecticism when primed by the written Chinese language and perceive more variations in their personality and behavior by themselves and others when primed by the spoken Chinese language and the ethnicity of a Chinese interlocutor. Hence, using the Chinese language guides bilinguals' lens to see ambivalence and inconsistency in personality traits and communicative behavior, which are manifestations of dialectical thinking. In this sense, language shapes cognitive processes. Since greater variability displayed by bilinguals while using Chinese can be detected by their conversation partners and outsiders, even without hearing their voice, it is not just subjective representations of dialectical thinking in their mind, but also outward traces in their communicative behavior. 
As Study 4 indicates, language effects are related to cultural characteristics and orientations. Embedded in cultural systems, language use carries shared knowledge and meanings as well as norms within the community. Cross-linguistic variations reflect differentiated ways of thinking in a culturally rooted style. By and large, prior studies using the thin-slicing method have gauged participants' judgment on targets' personal characteristics, such as demographic variables and sexual orientation (Ambady \& Rosenthal, 1992). Recently, Hamamura and Li (2012) found that Western cultural identification is discernible based on thin slices of a brief video clip or still image. As cultural theory and research have investigated individualism and collectivism extensively in social cognition, our findings that cultural orientations may also be observable based on thin slices will shed light on future crosscultural studies, especially in the domain of person perception.

\section{Personality Perception Is Malleable}

Hong, Morris, Chiu, and Benet-Martínez (2000) observed that in cross-cultural research, the underlying assumption of using generalized constructs is that cultural influences are continual and constant; thus, cultural differences in cognition are assessed as stable individual differences between societies. Yet, the influence of culture on cognition can be dynamic and changeable, depending on the accessibility of the construct to the mind and the construct's applicability to the situation (Hong, Benet-Martínez, Chiu, \& Morris, 2003). Individuals who internalize two cultures switch the cultural frame that they use to interpret social information and produce responses relevant to the primed culture.

Furthermore, the culture-as-situated-cognition model (Oyserman, 2011; Oyserman, Sorensen, Reber, \& Chen, 2009) argued that cultural differences in cognitive content and processes are better understood as malleable in whether a cultural mindset (individualistic or collectivistic) is cued in the moment, rather than being fixed and chronic cross-cultural differences in cultural orientations. Cultural priming studies have shown that individualistic primes evoke cognitive processes consistent with Western response patterns, such as focus on objects and figures instead of relationships and grounds, whereas collectivistic primes activate cognitive processes in line with East Asian patterns, such as emphasis on contexts and field dependence (Oyserman \& Lee, 2008). The variability of dialectical thinking and personality perception within individuals found in the present research adds more dependent variables, especially perception variations, to the cultural priming framework.

The present research is an attempt to understand how key cultural variables like dialecticism operate in bilingual contexts. Cognition is only one of the outcomes of bilingualism (Bialystok, Craik, Green, \& Gollan, 2009). Further studies may extend the research from bilingual to multilingual contexts. Since the reliability of the written measures in English is lower than those in Chinese, an alternative explanation for the current findings seems to be that using one's first language enables a more precise, expressive presentation of the self and thus more variability. On the other hand, in Dewaele and Nakano's (2013) study, multilinguals reported different feelings when switching languages. Dewaele and Wei (2013) found a link between multilingualism and tolerance of ambiguity, the personality trait of perceiving ambiguous situations or stimuli as desirable. They argued that exposure to and knowledge of foreign languages force multilinguals to become more attuned to differences and more aware that interlocutors may not share their values, beliefs, and communicative practices. It awaits future research to answer whether first-language usage or multilingualism affords a more diverse dispositional and behavioral repertoire.

Language effects on self-views, personality perception, and communicative behavior have important implications for intercultural contact. Under the influence of dialectical thinking, East Asians tend to exhibit more inconsistencies and incongruities when using different languages, and these patterns may cause interpersonal conflict and inevitable confusion when interacting with non-Asian audiences (Ting-Toomey, 1999). Our findings show that behaving and communicating differently across contexts are culturally rooted styles of being responsive to situational demands and constraints, not necessarily meaning that they are deceptive in nature or misleading on purpose. In fact, ambivalence and inconsistency characterize East Asians' own self-beliefs, and they are less stressed by this psychological complexity, hence with less adverse effects on their mental health than Westerners. Future research may explore whether and how language use affects subjective wellbeing, especially under the influences of globalization. The languages we speak shape the way we see ourselves and the world, the way we think and act, and perhaps the way we evaluate our lives.

\section{References}

Ambady, N., \& Rosenthal, R. (1992). Thin slices of expressive behavior as predictors of interpersonal consequences: A meta-analysis. Psychological Bulletin, 111, 256-274.

Bagozzi, R. P., Wong, N., \& Yi, Y. (1999). The role of culture and gender in the relationship between positive and negative affect. Cognition and Emotion, 13, 641-672.

Baron, R. M., \& Kenny, D. A. (1986). The moderator-mediator variable distinction in social psychological research: Conceptual, strategic and statistical considerations. Journal of Personality and Social Psychology, 51, 1173-1182.

Basseches, M. (1984). Dialectical thinking and adult development. Norwood, NJ: Ablex.

Berry, J. W. (1990). Psychology of acculturation. In N. R. Goldberger \& J. B. Veroff (Eds.), The culture and psychology reader (pp. 457-488). New York: New York University Press. (Reprinted from Nebraska symposium on motivation: Cross-cultural perspectives, by J. J. Berman, Ed., 1989, Lincoln: University of Nebraska Press) 
Bialystok, E., Craik, F. I. M., Green, D. W., \& Gollan, T. H. (2009). Bilingual minds. Psychological Science in the Public Interest, 10, 89-129.

Benet-Martínez, V., \& Haritatos, J. (2005). Bicultural identity integration (BII): Components and psychological antecedents. Journal of Personality, 73, 1015-1050.

Berlin, B., \& Kay, P. (1969). Basic color terms: Their universality and evolution. Berkeley: University of California Press.

Bernieri, F. J., \& Gillis, J. S. (2001). Judging rapport: Employing Brunswik's lens model to study interpersonal sensitivity. In J. A. Hall \& F. J. Bernieri (Eds.), Interpersonal sensitivity: Theory and measurement (pp. 67-88). Mahwah, NJ: Erlbaum.

Bond, M. H. (1983). How language variation affects inter-cultural differentiation of values by Hong Kong bilinguals. Journal of Language and Social Psychology, 2, 57-66.

Boroditsky, L. (2009). How does our language shape the way we think? In M. Brockman (Ed.), What's next? Dispatches on the future of science (pp. 116-129). New York, NY: Vintage Press.

Boroditsky, L., \& Gaby, A. (2010). Remembrances of times East: Absolute spatial representations of time in an Australian Aboriginal community. Psychological Science, 21, 1635-1639.

Boucher, H. C., \& O'Dowd, M. C. (2011). Language and the bicultural dialectical self. Cultural Diversity and Ethnic Minority Psychology, 17, 211-216.

Boucher, H. C., Peng, K., Shi, J., \& Wang, L. (2009). Culture and implicit self-esteem: Chinese are "good" and "bad" at the same time. Journal of Cross-Cultural Psychology, 40, 24-45.

Brown, R. (1986). Social psychology: The second edition. New York: Free Press.

Campbell, J. D., Trapnell, P. D., Heine, S. J., Katz, I. M., Lavallee, L. F., \& Lehman, D. R. (1996). Self-concept clarity: Measurement, personality correlates, and cultural boundaries. Journal of Personality and Social Psychology, 70, 141-156.

Chen, S., English, T., \& Peng, K. (2006). Self-verification and contextualized self-views. Personality and Social Psychology Bulletin, 32, 930-942.

Chen, S. X., Benet-Martínez, V., \& Bond, M. H. (2008). Bicultural identity, bilingualism, and psychological adjustment in multicultural societies: Immigration-based and globalization-based acculturation. Journal of Personality, 76, 803-838.

Chen, S. X., Benet-Martínez, V., Wu, W. C. H., Lam, B. C. P., \& Bond, M. H. (2013). The role of dialectical self and bicultural identity integration in psychological adjustment. Journal of Personality, 81, 61-75.

Chen, S. X., \& Bond, M. H. (2010). Two languages, two personalities? Examining language effects on the expression of personality in a bilingual context. Personality and Social Psychology Bulletin, 36, 1514-1528.

Cheng, C. (2009). Dialectical thinking and coping flexibility: A multimethod approach. Journal of Personality, 77, 471-493.

Cheung, G. W., \& Rensvold, R. B. (2002). Evaluating goodness-of-fit indexes for testing measurement invariance. Structural Equation Modeling: A Multidisciplinary Journal, 9, 233-255.

Chiu, C.-Y., Leung, A. K.-Y., \& Kwan, L. (2007). Language, cognition, and culture: Beyond the Whorfian hypothesis. In S. Kitayama
\& D. Cohen (Eds.), The handbook of cultural psychology (pp. 668-688). New York: Guilford Press.

Choi, I., \& Choi, Y. (2002). Culture and self-concept flexibility. Personality and Social Psychology Bulletin, 28, 1508-1517.

Chomsky, N. (1965). Aspects of a theory of syntax. Cambridge, MA: MIT Press.

Church, A. T., Anderson-Harumi, C., del Prado, A. M., Curtis, G. J., Tanaka-Matsumi, J., Valdez-Medina, J. L., et al. (2008). Culture, cross-role consistency, and adjustment: Testing trait and cultural psychology perspectives. Journal of Personality and Social Psychology, 95, 739-755.

Dewaele, J.-M., \& Nakano, S. (2013). Multilinguals' perceptions of feeling different when switching languages. Journal of Multilingual and Multicultural Development, 34, 107-120.

Dewaele, J.-M., \& Wei, L. (2013). Is multilingualism linked to a higher tolerance of ambiguity? Bilingualism: Language \& Cognition, 16, 231-240.

English, T., \& Chen, S. (2007). Culture and self-concept stability: Consistency across and within contexts among Asian Americans and European Americans. Journal of Personality and Social Psychology, 93, 478-490.

Fausey, C., \& Boroditsky, L. (2011). Who dunnit? Cross-linguistic differences in eye-witness memory. Psychonomic Bulletin \& Review, 18, 150-157.

Foster-Cohen, S. H. (1999). An introduction to child language development. London: Longman.

Hamamura, T., Heine, S. J., \& Paulhus, D. L. (2008). Culture differences in response styles: The role of dialectical thinking. Personality and Individual Differences, 44, 932-942.

Hamamura, T., \& Li, M. W. (2012). Discerning cultural identification from a thinly sliced behavioural sample. Personality and Social Psychology Bulletin, 38, 1698-1707.

Ho, D. Y. F., \& Chiu, C. Y. (1994). Component ideas of individualism, collectivism, and social organization: An application in the study of Chinese culture. In U. Kim, H. C. Triandis, C. Kagitcibasi, S. Choi, \& G. Yoon (Eds.), Individualism and collectivism: Theory, method, and applications (Cross-Cultural Research and Methodology, No. 18, pp. 137-156). Thousand Oaks, CA: Sage.

Hong, Y., Benet-Martínez, V., Chiu, C., \& Morris, M. (2003). Boundaries of cultural influence: Construct activation as a mechanism for cultural differences in social perception. Journal of CrossCultural Psychology, 34, 453-464.

Hong, Y. Y., Morris, M. W., Chiu, C. Y., \& Benet-Martínez, V. (2000). Multicultural minds: A dynamic constructivist approach to culture and cognition. American Psychologist, 55, 709-720.

Hoyle, R. H. (1995). Structural equation modeling: Concepts, issues, and applications. Thousand Oaks, CA: Sage.

Hui, C. H., \& Cheng, I. W. M. (1987). Effects of second language proficiency of speakers and listeners on person perception and behavioral intention: A study of Chinese bilinguals. International Journal of Psychology, 22, 421-430.

Hui, C. M., Fok, H. K., \& Bond, M. H. (2009). Who feels more ambivalence? Linking dialectical thinking to mixed emotions. Personality and Individual Differences, 46, 493-498. 
Ji, L., Peng, K., \& Nisbett, R. E. (2000). Culture, control, and perception of relationships in the environment. Journal of Personality and Social Psychology, 78, 943-955.

John, O. P. (1990). The Big Five factor taxonomy: Dimensions of personality in the natural language and in questionnaires. In L. A. Pervin (Ed.), Handbook of personality: Theory and research (pp. 66-100). New York: Guilford Press.

John, O. P., \& Robins, R. W. (1993). Determinants of interjudge agreement on personality traits: The Big Five domains, observability, evaluativeness, and the unique perspective of the self. Journal of Personality, 61, 521-551.

John, O. P., \& Srivastava, S. (1999). The Big Five trait taxonomy: History, measurement, and theoretical perspectives. In L. A. Pervin \& O. P. John (Eds.), Handbook of personality: Theory and research (2nd ed., pp. 102-138). New York: Guilford Press.

Judd, C. M., \& Kenny, D. A. (1981). Process analysis: Estimating mediation in treatment evaluations. Evaluation Review, 5, 602 619.

Kanagawa, C., Cross, S. E., \& Markus, H. R. (2001). "Who am I?" The cultural psychology of the conceptual self. Personality and Social Psychology Bulletin, 27, 90-103.

Kashima, Y., Kashima, E. S., Chiu, C., Farsides, T., Gelfand, M. J., Hong, Y., et al. (2005). Culture, essentialism, and agency: Are individuals universally believed to be more real entities than groups? European Journal of Social Psychology, 35, 147169.

Kay, P., \& Kempton, W. (1984). What is the Sapir-Whorf hypothesis? American Anthropologist, 86, 65-79.

Kitayama, S., \& Cohen, D. (Eds.). (2007). Handbook of cultural psychology. New York: Guilford Press.

Kitayama, S., Duffy, S., Kawamura, T., \& Larsen, J. T. (2003). Perceiving an object and its context in different cultures: A cultural look at new look. Psychological Science, 14, 201-206.

Levinson, S. C. (1996). Language and space. Annual Review of Anthropology, 25, 353-382.

Lew, W. J. F. (1985). Traits and dimensions of personality: Chinese intellectuals in Taiwan. CUHK Education Journal, 13, 37-48.

Lucy, J. A. (1992). Language diversity and thought: A reformulation of the linguistic relativity hypothesis. Cambridge: Cambridge University Press.

Lucy, J. A. (1997). The linguistics of "color.” In C. L. Hardin \& L. Maffi (Eds.), Color categories in thought and language (pp. 320436). Cambridge: Cambridge University Press.

Marin, G., Triandis, H. C., Betancourt, H., \& Kashima, Y. (1983). Ethnic affirmation versus social desirability: Explaining discrepancies in bilinguals' responses to a questionnaire. Journal of Cross-Cultural Psychology, 14, 173-186.

Markus, H. R., \& Kitayama, S. (1991). Culture and the self: Implications for cognition, emotion, and motivation. Psychological Review, 98, 224-253.

Masuda, T., \& Nisbett, R. E. (2001). Attending holistically versus analytically: Comparing the context sensitivity of Japanese and Americans. Journal of Personality and Social Psychology, 81, 922-934.
Matsumoto, D., \& Assar, M. (1992). The effects of language on judgments of universal facial expressions of emotions. Journal of Nonverbal Behavior, 16, 85-99.

McCrae, R. R., \& Costa, P. T., Jr. (1985). Openness to experience. In R. Hogan \& W. H. Jones (Eds.), Perspectives in personality (Vol. 1, pp. 145-172). Greenwich, CT: JAI Press.

McCrae, R. R., \& Costa, P. T., Jr. (1987). Validation of the five-factor model of personality across instruments and observers. Journal of Personality and Social Psychology, 52, 81-90.

Mishra, R. C. (2001). Cognition across cultures. In D. Matsumoto (Ed.), The handbook of culture and psychology (pp. 119-136). New York: Oxford University Press.

Moshman, D. (1995). Reasoning as self-constrained thinking. Human Development, 38, 53-64.

Muthén, L. K., \& Muthén, B. O. (2007). Mplus statistical analysis with latent variables user's guide (5th ed.). Los Angeles: Muthén \& Muthén.

Nisbett, R. E. (2003). The geography of thought: How Asians and Westerners think differently ... and why. New York: Free Press.

Nisbett, R. E., Peng, K., Choi, I., \& Norenzayan, A. (2001). Culture and systems of thought: Holistic versus analytic cognition. Psychological Review, 108, 291-310.

Norman, W. T. (1963). Toward an adequate taxonomy of personality attributes: Replicated factor structure in peer nomination personality ratings. Journal of Abnormal and Social Psychology, 66 , 574-583.

Oltmanns, T. F., Friedman, J. N. W., Fiedler, E. R., \& Turkheimer, E. (2004). Perceptions of people with personality disorders based on thin slices of behavior. Journal of Research in Personality, $\mathbf{3 8}$, 216-229.

Oyserman, D. (2011). Culture as situated cognition: Cultural mindsets, cultural fluency and meaning-making. European Review of Social Psychology, 22, 164-214.

Oyserman, D., \& Lee, S. (2008). Does culture influence what and how we think? Effects of priming individualism and collectivism. Psychological Bulletin, 34, 311-342.

Oyserman, D., Sorensen, N., Reber, R., \& Chen, S. X. (2009). Connecting and separating mindsets: Culture as situated cognition. Journal of Personality and Social Psychology, 97, 217 235.

Özgen, E. (2004). Language, learning, and color perception. Current Directions in Psychological Science, 13, 95-98.

Pavlenko, A. (Ed.). (2011). Thinking and speaking in two languages. Bristol, UK: Multilingual Matters.

Peng, K., \& Nisbett, R. E. (1999). Culture, dialectics, and reasoning about contradiction. American Psychologist, 54, 741-754.

Pinker, S. (1994). The language instinct: How the mind creates language. New York: HarperCollins.

Ramírez-Esparza, N., Gosling, S. D., Benet-Martínez, V., Potter, J. P., \& Pennebaker, J. W. (2006). Do bilinguals have two personalities? A special case of cultural frame switching. Journal of Research in Personality, 40, 99-120.

Roberson, D., Davies, I., \& Davidoff, J. (2000). Color categories are not universal: Replications and new evidence from a Stone-Age 
culture. Journal of Experimental Psychology: General, 129, 369398.

Satorra, A., \& Bentler, P. M. (1988). Scaling corrections for chisquare statistics in covariance structure analysis. In ASA 1988 Proceedings of the Business and Economic Statistics Section (pp. 308-313). Alexandria, VA: American Statistical Association.

Schwartz, S. H. (1994). Cultural dimensions of values: Toward an understanding of national differences. In U. Kim, H. C. Triandis, C. Kagitcibasi, S. C. Choi, \& G. Yoon (Eds.), Individualism and collectivism: Theory, method, and applications (pp. 85-121). Thousand Oaks, CA: Sage.

Semin, G. R. (2001). Language and social cognition. In A. Tesser \& N. Schwarz (Eds.), Handbook of social psychology: Intraindividual Processes (Vol. 1, pp. 159-180). Oxford: Blackwell.

Sobel, M. E. (1982). Asymptotic confidence intervals for indirect effects in structural equation models. Sociological Methodology, 13, 290-312.

Spencer-Rodgers, J., Boucher, H. C., Mori, S. C., Wang, L., \& Peng, K. (2009). The dialectical self-concept: Contradiction, change, and holism in East Asian cultures. Personality and Social Psychology Bulletin, 35, 29-44.

Spencer-Rodgers, J., Srivastava, S., Boucher, H. C., English, T., Paletz, S. B., \& Peng, K. (2010). [The Dialectical Self Scale]. Unpublished data. University of California at Berkeley.

Spencer-Rodgers, J., Williams, M. J., \& Peng, K. (2010). Cultural differences in expectations of change and tolerance for contradiction: A decade of empirical research. Personality and Social Psychology Review, 14, 296-312.
Sternberg, R. J. (1999). Cognitive psychology. New York: Harcourt Brace.

Suh, E. M. (2002). Culture, identity consistency, and subjective wellbeing. Journal of Personality and Social Psychology, 83, 13781391.

Ting-Toomey, S. (1999). Communicating across cultures. New York: Guilford Press.

Trafimow, D., Silverman, E., Fan, R., \& Law, J. (1997). The effects of language and priming on the relative accessibility of the private self and the collective self. Journal of Cross-Cultural Psychology, 28, 107-123.

Triandis, H. C. (1989). The self and social behavior in differing cultural contexts. Psychological Review, 96, 506-520.

Triandis, H. C. (1993). Collectivism and individualism as cultural syndromes. Cross-Cultural Research, 27, 155-180.

Whorf, B. I. (1956). Language, thought, and reality. Cambridge, MA: MIT Press.

Wiggins, J. S. (1973). Personality and prediction: Principles of personality assessment. Reading, MA: Addison-Wesley.

Wright, J. C., \& Drinkwater, M. (1997). Rationality vs. accuracy of social judgment. Social Cognition, 15, 245-273.

Yang, K. S., \& Bond, M. H. (1990). Exploring implicit personality theories with indigenous or imported constructs: The Chinese case. Journal of Personality and Social Psychology, 58, 10871095.

Yik, M. S. M., \& Bond, M. H. (1993). Exploring the dimensions of Chinese person perception with indigenous and imported constructs: Creating a culturally balanced scale. International Journal of Psychology, 28, 75-95. 